\title{
Dentigeruos cyst and dental dislocation: when the surgical technique can avoid orthodontic disinclusive treatment
}

\author{
Laffi Nicola ${ }^{1}$, Capurro Claudia $^{1 *}$, Merlino Emilia ${ }^{2}$ and Chiappe Marco Davide Giacomo ${ }^{2}$ \\ ${ }^{1}$ Department of Pediatric Odontostomatology and Orthodontics, G.Gaslini Hospital, Genoa, Italy \\ ${ }^{2}$ Hospital Visitor Dentist, Department of Pediatric Odontostomatology and Orthodontics, G.Gaslini Hospital, Genoa, Italy
}

\begin{abstract}
The dentigerous cyst (DC) is one of the most common cystic lesions that can be observed in the jaw and is associated with the crown of an included or impacted tooth. Radiographically it appears as a unilocular radiolucency surrounding the crown of an included or impacted tooth with a well-defined sclerotic edge.

The pathogenesis of DC is controversial, in most cases it is of disembriogenetic origin, but it can also have inflammatory pathogenesis starting from a compromised deciduous element.
\end{abstract}

The DC has development and asymptomatic course, for this reason it can reach considerable dimensions, involving adjacent noble structures, can lead to dislocation of contiguous dental elements or to deformation of the marginal bone profile.

The therapeutic options are: surgical excision of the cyst or marsupialization.

The objective of this study is to demonstrate how marsupialization is a conservative treatment for the dental element involved in the cystic lesion, able to promote its spontaneous eruption.

The authors report 4 cases of large-sized dentigerous cysts, localized apically to infected deciduous elements, with dislocation of the immature permanent teeth involved.

The cases were treated by extraction of the deciduous elements and marsupialization of the cystic cavity.

After surgery, radiographic checks were performed through Orthopantomography.

The dental elements are completely erupted without disinclusive orthodontic therapy.

The clinical results obtained are supported by the literature indicating marsupialization as a conservative treatment in case of dentigerous cysts to favor the spontaneous eruption of the involved elements and the healing of the cystic lesion.

\section{Introduction}

The dentigerous cyst (DC) is one of the most frequently observed cystic lesions in the mandible [1-3]. It is an odontogenic cyst associated with the crown of an included or impacted tooth.

The pathogenesis of DC is controversial, in most cases it appears to have disembriogenetic origin: it is caused by an alteration of the reduced enamel epithelium at the end of the amelogenesis process which causes an accumulation of liquids between the epithelium and the crown of the permanent tooth $[4,5]$.

Another hypothesis is that it has an inflammatory origin. Azaz and Shteyer affirm that the lasting presence of inflammation due for example to a compromised deciduous element can cause a chronic irritation of the included or impacted tooth follicle that can evolve in an accumulation of exudate and then in a DC [6].

Benn and Altini have shown that even a histologically separation between the reduced enamel epithelium and the crown of the tooth can be observed in the presence of inflammatory exudate [4].

DC is more common in male patients and develops more frequently in the second or third decade of life [7-9].
The mandibular third molar is the most frequently involved tooth, then there are second molars and mandibular premolars, supernumerary teeth and odontomas [10].

Clinically it can be observe a localized deformation at the level of the alveolar bone or a dislocation of the contiguous dental elements [11].

It can be asymptomatic for a long period of time causing a great destruction of bone [12]. For this reason the initial diagnosis of DC is usually placed during a routine radiograph and the suspicion arises if the lesion exceeds $5 \mathrm{~mm}$ in diameter [13]. It is then confirmed if the histological examination shows the presence of non-keratinized stratified squamous epithelium delimiting the cystic lumen $[8,9]$.

The two main therapeutic options are surgical excision and marsupialization.

${ }^{*}$ Correspondence to: Claudia Capurro, MD, Department of Pediatric Odontostomatology and Orthodontics, G.Gaslini Hospital, Genoa, Italy, Tel: +393388122372; E-mail: horseiron@libero.it

Received: February 24, 2020; Accepted: March 02, 2020; Published: March 05, 2020 
If the objective is the preservation of the dental element in a young patient with an isolated lesion, marsupialization is recommended as a conservative treatment able to promote the spontaneous eruption of the tooth $[9,14-17]$.

\section{Case report}

Case 1. A 10 years old male patient presented with a 1 month history of mandibular swelling on the right, asymptomatic. Performed Ortopanthomography and mandibular TCCB an osteolytic lesion is observed that extends from 8.5 to 8.2 with dislocation and retention of 43, 44 and 45 (Figure 1).

On the physical examination there is a visible mandibular swelling and a wide engagement of the vestibular fornix. 8.4,8.3 and 8.2 are still present in the arch and they have endodontical treatment done. To palpation it can be appreciate a deformation of the contour with sign of crackling.

In consideration of the age of the patient and the potential for growth, a marsupialization of the cystic lesion is proposed with avulsion of the deciduous elements involved in the area of the lesion following which a lingual arch is applied to maintain the space for erupting teeth .

In the first year after the surgery it has been checked the progress of the healing every three months with a Ortopantomography (Figures 2-4). It has seen a reduction in cystic volume and a spontaneous eruption process. One year and half after the surgery a ortopantomography was performed and no cystic lesion was observed. 4.3, 4.4, 4.5 was completely erupted (Figure 5).

Case 2. A 8 years old male patient presented with a history of mandibular swelling on the left, asymptomatic. Performed Ortopanthomography and mandibular TCCB an osteolytic lesion is observed with dislocation and retention of 4.2.

On the physical examination there is a visible mandibular swelling on the left and a wide engagement of the vestibular fornix. 7.5 and 7.4 are still present in the arch and they have endodontical treatment done. To palpation it can be appreciate a deformation of the contour with sign of crackling, without mobility (Figure 6).

Marsupialization of the cystic lesion with avulsion of the deciduous elements involved in the lesion area is proposed, following which a lingual arch is applied to maintain the space for erupting teeth. After three and six months Ortopantomography was performed in order to check the evolution of the healing process and the eruption of the impacted tooth (Figures 7 and 8). Nine months from surgery 4.2 erupted and no cyst lesion was observed (Figure 9).

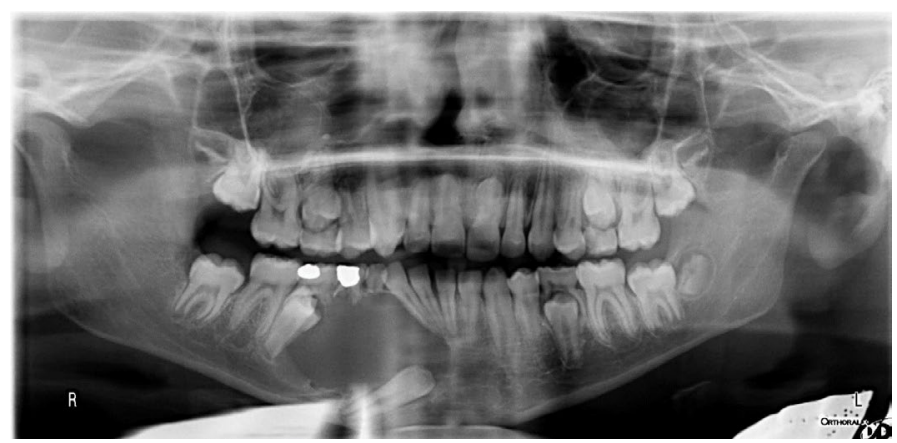

Figure 1 Case 1. Initial Ortopantomography

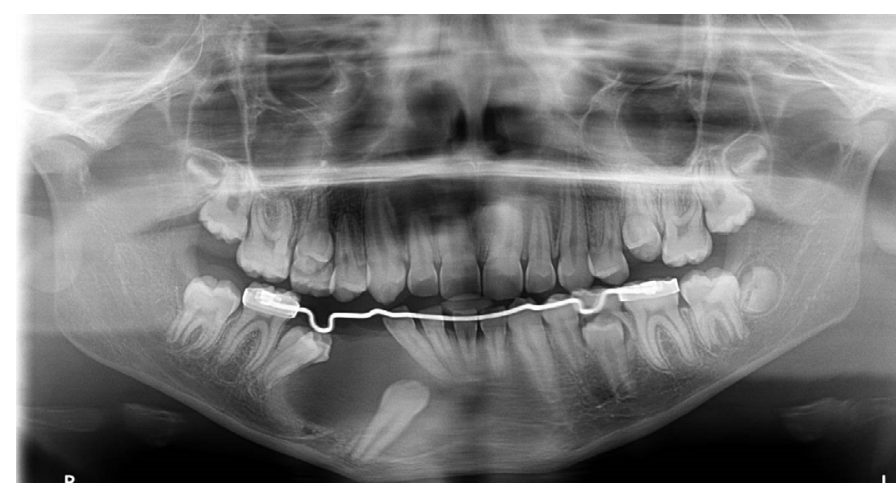

Figure 2 Case 1. Three months after the marsupialization

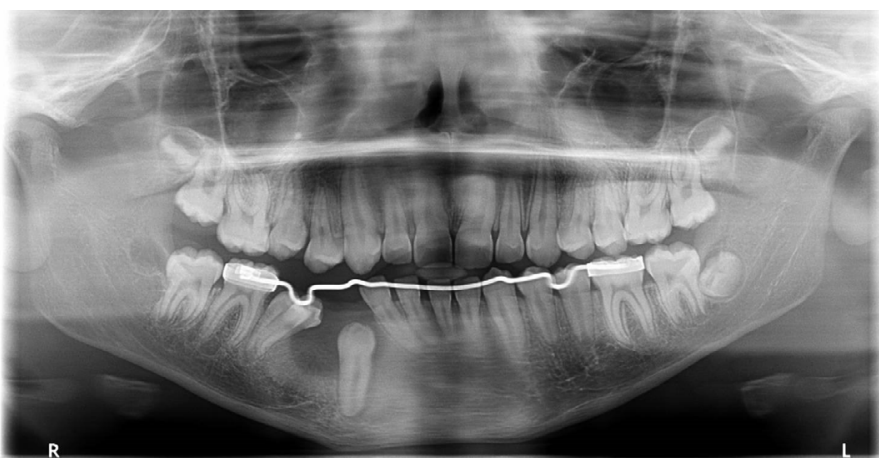

Figure 3 Case 1. Six months after marsupialization

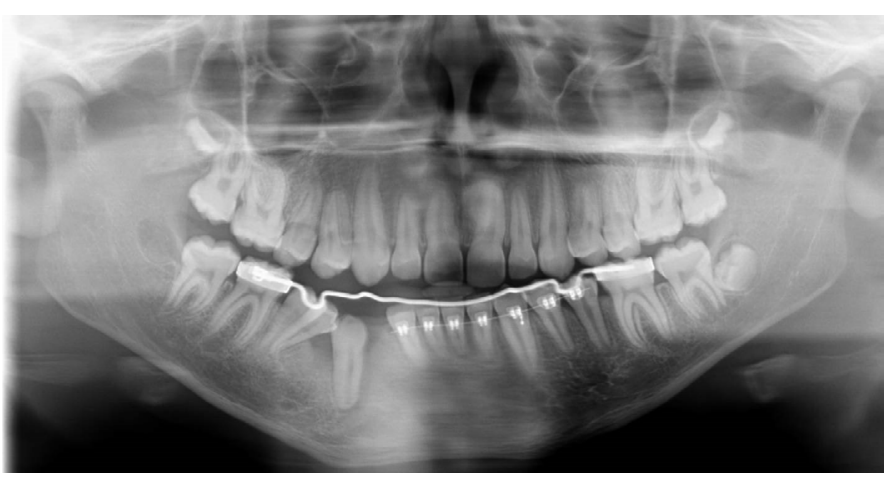

Figure 4 Case 1. Nine months after marsupialization

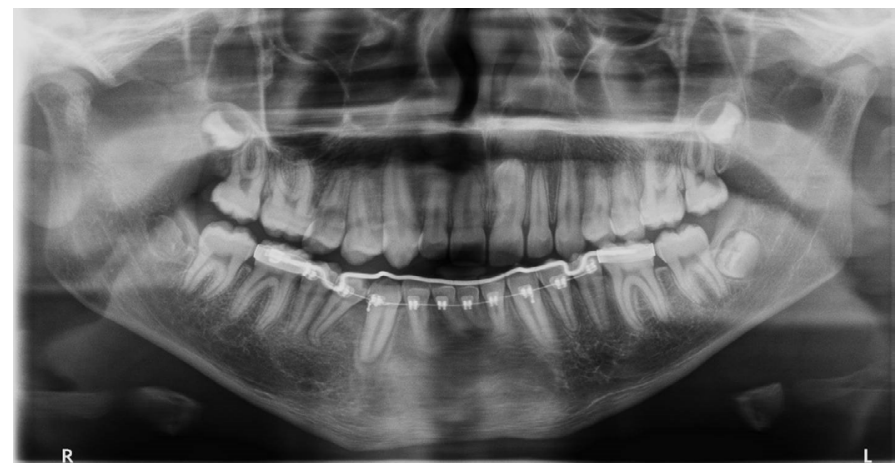

Figure 5 Case 1. After one year and a half there is no cystic lesion and the element displaced are erupted

Case 3. A 9 years old female patient presented with delay of the eruption of the 2.6. Performed Ortopanthomography and mandibular TCCB an osteolytic lesion is observed with medially displacement of the 2.1 and 2.2 (Figure 10). 
Marsupialization of the cystic lesion with avulsion of the deciduous elements (6.1,6.2 and 6.3) involved in the lesion area is proposed.

Ten months after the avulsion of deciduous teeth Ortopantomography was performed in order to check the evolution of the healing process and the eruption of the displaced tooth (Figure 11).

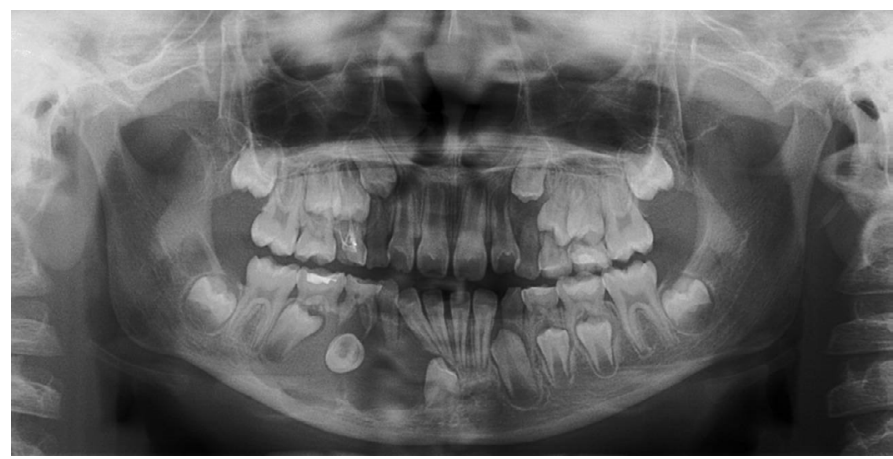

Figure 6 Case 2. Initial ortopantomography

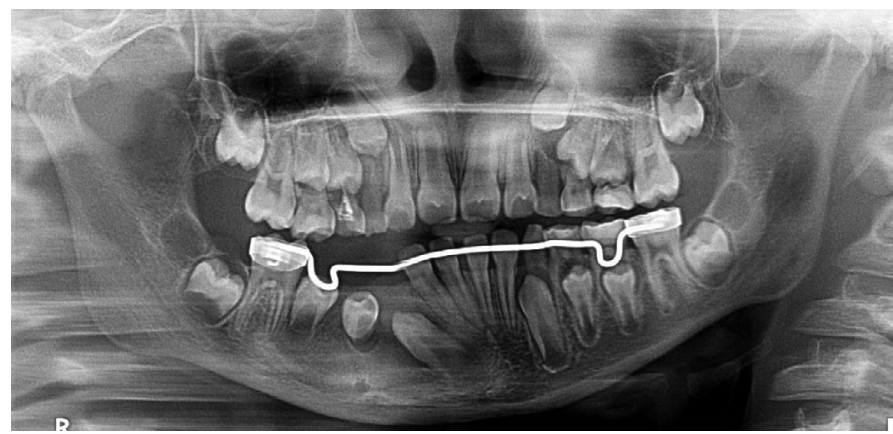

Figure 7 Case 2. Three months after marsupialization

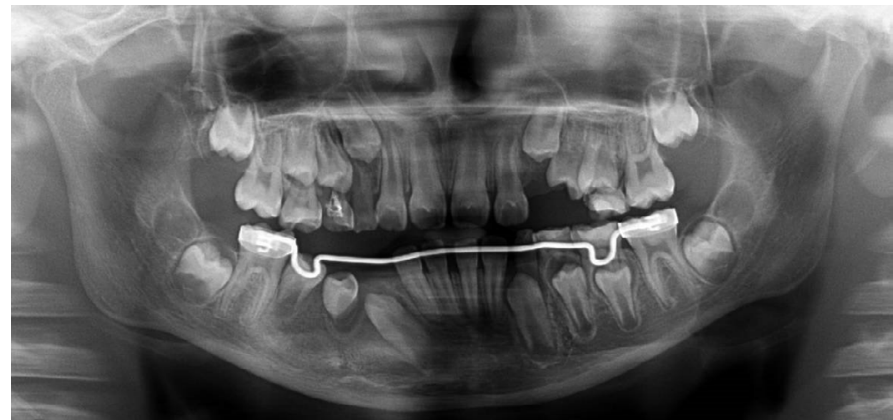

Figure 8 Case 2. Six months after marsupialization.

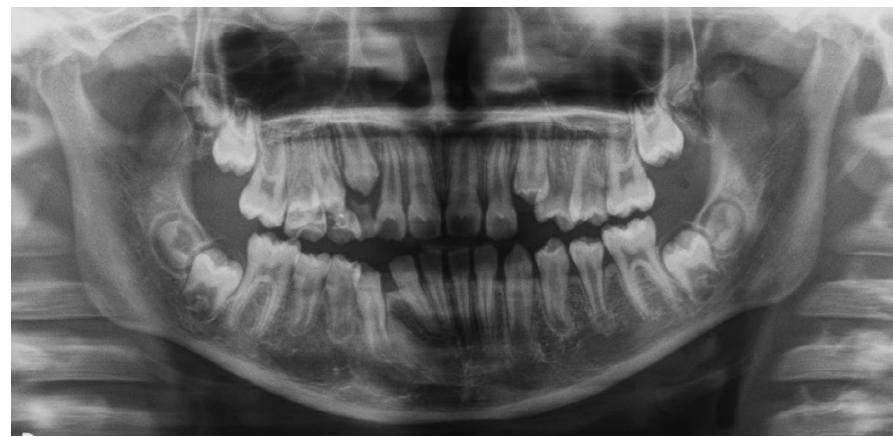

Figure 9 Case 2. After nine months there is no cystic lesion and the element displaced are erupted

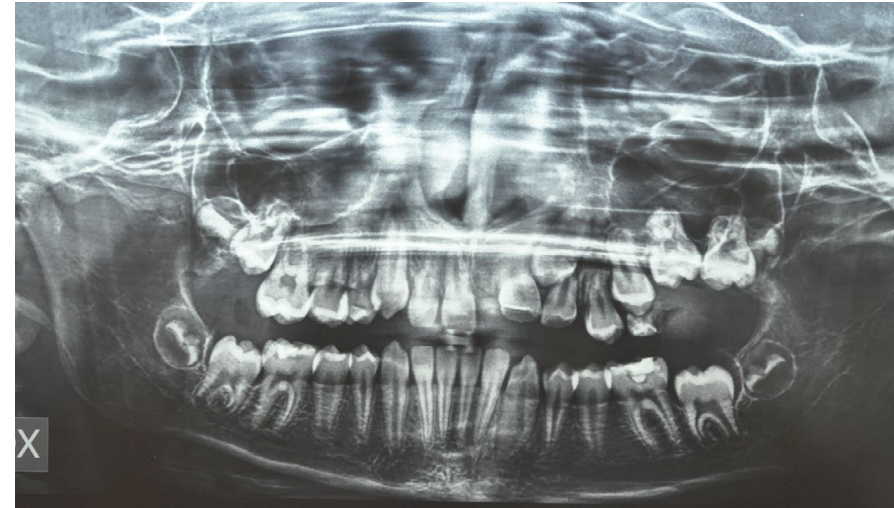

Figure 10 Case 3. Initial ortopantomography

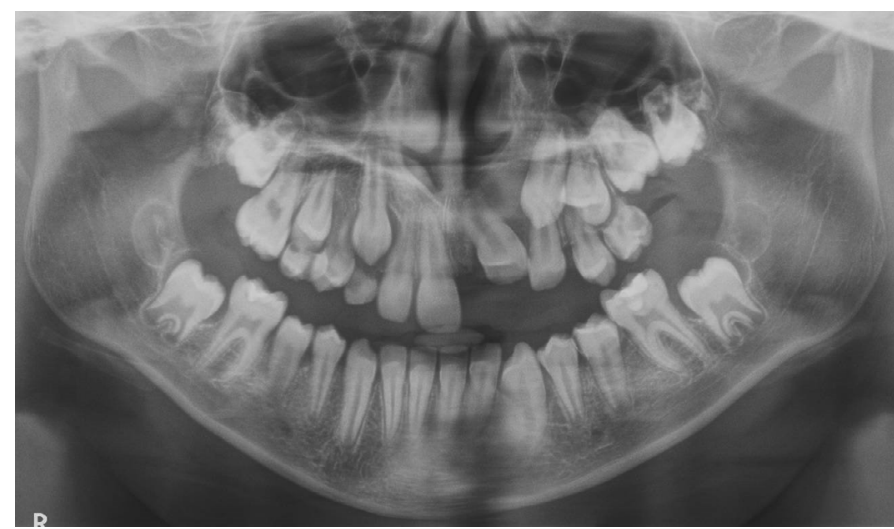

Figure 11 Case 3. Three months after the marsupialization

After the eruption of the involved teeth and in order to check the progress, another ortopantomography was performed. No cyst lesion was observed (Figure 12).

Case 4. A 9 years old male patient was sent to the attention of the specialist in the Department of Pediatric Odontostomatology and Orthodontics in the G.Gaslini Hospital from a freelance dentist because he has found in a Ortopantomography done for check the eruption progress a osteolytic lesion on the left side of the jaw.

On the ortopantomography multiple root leavings was found and a osteolytic mandibular lesion in the apical area of the 7.4 with dislocation of permanent teeth compatible with a diagnosis of dentigeruous cyst.

Marsupialization and biopsy was performed and a lingual arch is applied to maintain the space for erupting teeth. After three, six and nine months from the marsupialization ortopanthomography was done til to the eruption of the involved tooth (Figures 13-15).

\section{Discussion}

The dentigeruos cyst (DC) is one of the most frequently observed cystic lesions in the mandible $[1,2]$. In a study conducted on a sample of 695 patients suffering from odontogenic cysts, the two most frequent were radicular cysts (53.5\%) and dentigeruos cysts (22.3\%) [12].

DCs can cause serious resorption, expand into surrounding tissues and bone and dislocate adjacent dental elements causing malocclusions and facial asymmetries [18].

Paresthesia of the lower mandibular nerve caused by a DC has also been reported [19]. 


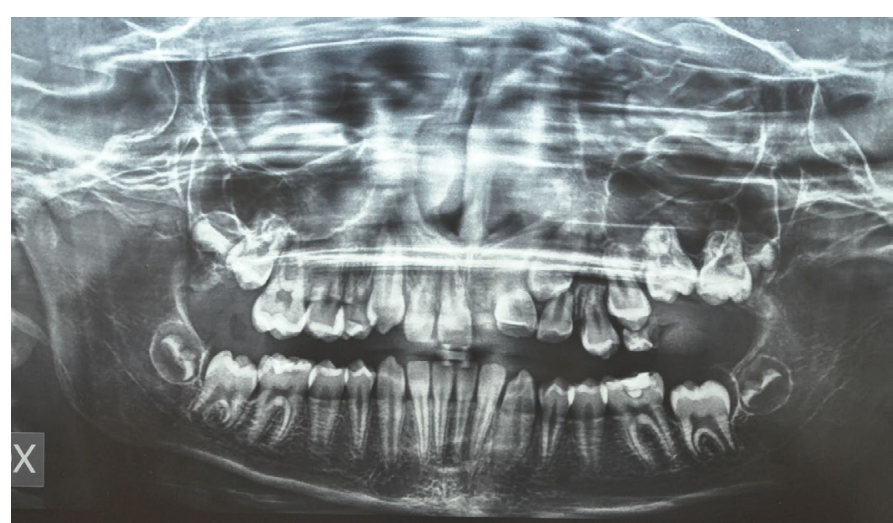

Figure 12 Case 3. After the eruption of the involved teeth. No cyst lesion was observed.

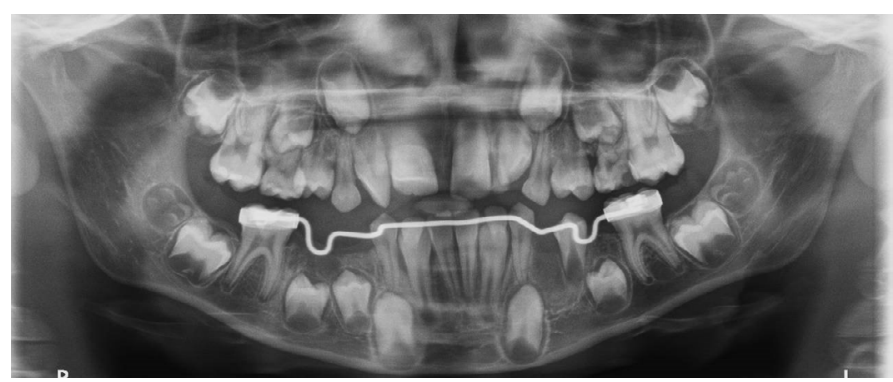

Figure 13 Case 4. Three months after the marsupialization

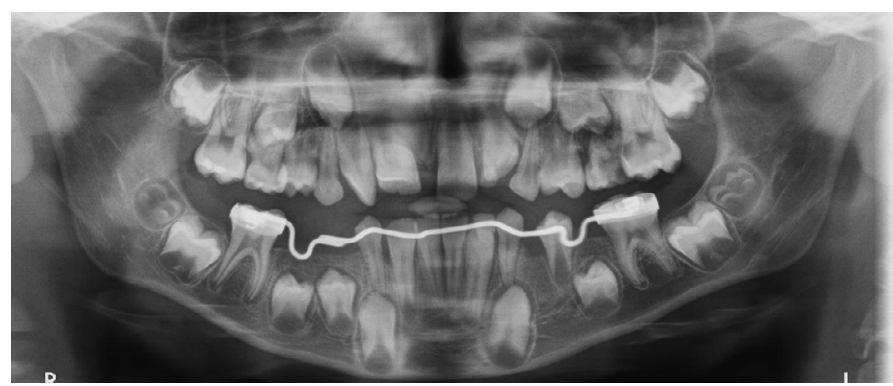

Figure 14 Case 4. Six months after the marsupialization

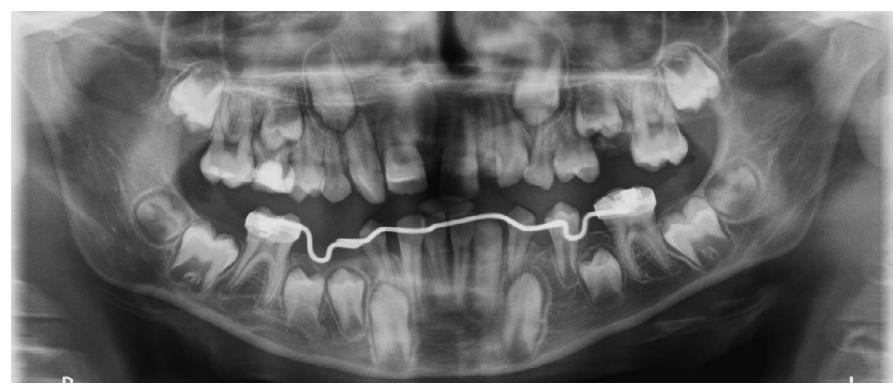

Figure 15 Case 4. After nine months the involved teeth were erupted

In most cases this lesion is asymptomatic and is diagnosed during routine radiographic examinations or performed for other reasons and appears as a well-defined radiolucency associated with the crown of a non-erupted tooth $[12,13]$.

The differential diagnosis involves hyperplastic dental follicles, Ameloblastoma, ameloblastic fibroma, keratocysts, intraosseous mucoepidermal carcinoma, radicular cysts and myxoma $[8,17,19]$.
The treatments for DC are excision or marsupialization Marsupialization has the advantage of preserving the permanent tooth involved in the cyst.

However in some cases at the discretion of the clinician it is appropriate to resort to complete excision, for example if the element involved is a supernumerary $[17,20,21]$.

Previous studies have shown that the inclination of the tooth involved in the cystic lesion in the alveolar bone, the development of the root and the space in the arch are predisposing factors to the marsupialization intervention because they increase the predictability of the spontaneous eruption of the element involved and therefore must be taken into consideration $[11,17]$

For example, in fact, an impacted tooth without a complete root formation with an apex root has a considerable potential of eruption $[11,17]$.

In cases where the element does not spontaneously erupt, considering 100 days as time limit, it is possible to decide whether to extract it or use an orthodontic traction $[17,22]$.

In the cases presenting the elements, they are erupted spontaneously after extracting the corresponding deciduous, using a lingual arch to preserve the space in the arch and having performed marsupialization surgery.

All predictive factors were favorable to spontaneous eruption.

The data obtained are coherent with what has already been observed in the literature where it reports the spontaneous eruption of the included dental elements or impacts without resorting to orthodontic traction $[9,23-26]$.

\section{References}

1. Shafer WG, Hine MK, Levy BM (1983) A textbook of oral pathology. (4th Edn) Philadelphia: WB Saunders pp. 260-265.

2. Regezi JA, Sciubba J (1993) Oral pathology: clinical-pathologic correlations. (2nd Edn) Philadelphia: WB Saunders pp. 326-332.

3. Ramandeep SN, Adesh SM, Preeti A, Kawar R (2012) Dentigerous cyst of inflammatory origin-a diagnostic dilemma. Ann Diagn Pathol 16: 119-123. [Crossref]

4. Benn A, Altini M (1996) Dentigerous cysts of inflammatory origin. A clinicopathologic study. Oral Surg Oral Med Oral Pathol Oral Radiol Endod 81: 203-209. [Crossref]

5. Brook AH, Winter GB (1975) Developmental arrest of permanent tooth germs following pulpal infection of deciduous teeth. Br Dent J 139: 9-11. [Crossref]

6. Azaz B, Shteyer A (1973) Dentigerous cysts associated with second mandibula bicuspids in children: report of five cases. J Dent Child 40: 29-31. [Crossref]

7. Waldron CA (2004) Odontogenics cysts and tumors. In: Nevile Bw, Damm DD, Allen CM, Bouquot JE (eds) Oral and maxillofacial pathology. Guanabara Koogan, Rio de Janeiro 566-569.

8. Martinez-Perez D, Varela-Morales M (2001) Conservative treatment of dentigerous cysts in children: a report of 4 cases. J Oral Maxillofac Surg 59: 331-334. [Crossref]

9. Ertas U, Yavuz S (2003) Interesting eruption of 4 teeth associated with a large dentigerous cyst in mandible by only marsupialization. J Oral Maxilofac Surg 61: 728730. [Crossref]

10. Mandel L (1997) Submasseteric abscess caused by a dentigerous cyst mimicking parotitis: report of two cases. J Oral Maxillofac Surg 55: 996-999. [Crossref]

11. Fujii R, Kawakami M, Hyomoto M, Ishida J, Kirita T (2008) Panoramic findings for predicting eruption of mandibular premolars associated with dentigerous cyst after marsupialization. J Oral Maxillofac Surg 66: 272-276. [Crossref]

12. Meningaud JP, Oprean N, Pitak-Arnnop P, Bertrand JC (2006) Odontogenic cysts: a clinical study of 695 cases. J Oral Sci 48: 59-62. [Crossref] 
13. Gondim JO, Moreira Neto JJS, Nogueira RLM, Giro EMA (2008) Conservative management of a dentigerous cyst secondary to primary tooth trauma. Dental Traumatol 24: 676-679. [Crossref]

14. Motamedi MH, Talesh KT (2005) Management of extensive dentigerous cysts. Br Dent $J$ 198: 203-206. [Crossref]

15. Koca H, Esin A, Aycan K (2009) Outcome of dentigerous cysts treated with marsupialization. J Clin Pediatr Dent 34: 165-168. [Crossref]

16. Tüzüm MS (1997) Marsupialization of a cyst lesion to allow tooth eruption: a case report. Quintessence Int 28: 283-284. [Crossref]

17. Miyawaki S, Hyomoto M, Tsubouchi J, Kirita T, Sugimura M (1999) Eruption speed and rate of angulation change of a cyst-associated mandibular second premolar after marsupialization of a dentigerous cyst. Am J Orthod Dentofac Orthoped 116: 578-584. [Crossref]

18. Dinkar AD, Dawasaz AA, Shenoy S (2007) Dentigerous cyst associated with multiple mesiodens: a case report. J Indian Soc Pedod Prev Dent 25: 56-59. [Crossref]

19. Summer M, Bas B, Yildiz L (2007) Inferior alveolar nerve par- esthesia caused by dentigerous cyst associated with three teeth. Med Oral Patol Oral Cir Bucal 12: 388390. [Crossref]
20. Düker J (2005) Dentigerous cyst associated with an impacted mandibular third molar. Quintessence Int 36: 487-489. [Crossref]

21. Shun Y (2008) Dentigerous cyst associated with an impacted anterior maxillary supernumerary tooth. J Dent Child Chic 75: 104-107.

22. Yahara Y, Kubota Y, Yamashiro T, Shirasuna K (2009) Eruption prediction of mandibular premolars associated with dentigerous cysts. Oral Surg Oral Med Oral Pathol Oral Radiol Endod 108: 28-31. [Crossref]

23. Mussi Milano Contar C, Thomè A, Pompermayer A, Sarto JR, Oliveira Vinagre R, et al. (2015) Marsupialization of dentigeruous Cyst: report of a case. J Maxillofac Oral Surg 14: 4-6. [Crossref]

24. Hyomoto M, Kawakami M, Inoue M, Kirita T (2003) Clinical conditions for eruption of maxillary canines and mandibular premolars associated with dentigerous cysts. $\mathrm{Am}$ J Orthod Dentofacial Orthop 124: 516-520. [Crossref]

25. Yu-Hsuan Hu, Yu-Liang Chang, Aileen Tsai (2011) Conservative treatment of dentigerous cyst associated with primary teeth. Oral Surg Oral Med Oral Pathol Oral Radiol Endod 112: 5-7. [Crossref]

26. Berti Sde A, Pompermayer AB, Couto Souza PH, Tanaka OM, Westphalen VP, et al. (2010) Spontaneous eruption of a canine after marsupialization of an infected dentigerous cyst. Am J Orthod Dentofacial Orthop 137: 690-693. [Crossref]

Copyright: (C2020 Nicola L. This is an open-access article distributed under the terms of the Creative Commons Attribution License, which permits unrestricted use, distribution, and reproduction in any medium, provided the original author and source are credited. 